\title{
The Perfect Storm
}

\section{Review: Immune Dysregulation in Severe COVID-19 and the Possible Role of Mast Cell-Vitamin D Interactions}

\author{
Annwyne Houldsworth* \\ Worked in Khalifa University, Abu Dhabi, United Arab Emirates
}

*Corresponding author: Annwyne Houldsworth, Worked in Khalifa University, Abu Dhabi, United Arab Emirates, Phone: +447377629783 ; E-mail: Annwyne.houldsworth@gmail.com

Received: 20 Jan, 2021 | Accepted: 11 Feb, 2021 | Published: 19 Feb, 2021

Citation: Houldsworth A (2021) The Perfect Storm: Review: Immune Dysregulation in Severe COVID-19 and the Possible Role of Mast CellVitamin D Interactions. J Emerg Dis Virol 6(1): dx.doi.org/10.16966/2473-1846.161

Copyright: (C) 2021 Houldsworth A. This is an open-access article distributed under the terms of the Creative Commons Attribution License, which permits unrestricted use, distribution, and reproduction in any medium, provided the original author and source are credited.

\begin{abstract}
COVID-19 is caused by a Severe Acute Respiratory Syndrome Coronavirus (SARS-CoV-2) and has two spike subunits on the envelope of SARS-CoV-2, S1 and S2, where S1 binds to the Angiotensin Converting Enzyme (ACE-2), a receptor on the host cells and S2 binds to the cell surface membrane. Different immune responses to the virus are apparent, from asymptomatic to severe respiratory distress, organ failure and ultimately death. Immune responses without hyper-inflammation are essential to successful viral resolution. Pathological and environmental factors drive the immunological repertoire, in response to the virus, influencing innate immune cell activation, cytokine-balance and T cell differentiation. This is determined by age, comorbidity, Vitamin D status and ethnicity related factors. Homeostasis of the immune system plays an important role in the development of COVID-19 pneumonia. Mast cell activation and release of histamine is important to the cytokine driven T-cell differentiation as the adaptive response. This review combines the relative effects of UV-index-related Vitamin-D synthesis with immune status. Innate immune responses, T cell differentiation and renin/angiotensin system are different in patients affected by COVID-19 and their different outcomes are explored.
\end{abstract}

Understanding the differences between individuals that determine disease outcome will greatly enhance future therapy methods.

Keywords: COVID-19; Innate immunity; Adaptive immunity; Cytokine; Interleukin; Mast cell; Histamine; Vitamin D; UV index; Th17; IL-17; Inflammation

\section{Introduction}

COVID-19 is a highly infectious and virulent disease caused by a Severe Acute Respiratory Syndrome Coronavirus (SARS-CoV-2). 381,000 people were infected in 195 countries or regions by $24^{\text {th }}$ March 2020, with many fatalities, when the WHO declared a global pandemic caused by SARS-CoV-2 [1].

This novel virus, of zoonotic origin, is a single stranded RNA coronavirus of about 129 nanometers in diameter, with the appearance of the corona surrounding the sun as we observe in an eclipse [2]. Four main subgroupings $(\alpha, \beta, \delta, \gamma)$ of coronavirus, in the subfamily of orthocoronavirinae, are identified so far. A new virus genome was sequenced in December of 2019, of the $\beta-\mathrm{CoV}$ strain and was isolated with $88 \%$ identity with two bat-derived sequences of a SARS-type coronavirus. The novel virus is subgenus Sarbeovirus (lineage B). There is only one amino acid difference between the spike binding protein of pangolins and humans. It is $96 \%$ genetically identical to the bat coronavirus (BatCov RaTG13) [3-5].

The surrounding envelope of SARS-CoV-2 is densely populated with an assembly of glycoproteins or peplomers that are positioned on the surface of the SARS-CoV-2 virion, known as spike or S-proteins [6-8].
The pathophysiology of COVID 19 involves virus particles invading the respiratory mucosa, triggering a series of immune responses and an over-activation of lymphocytes, with apoptosis or necrosis of the infected cells; producing a 'cytokine storm'. The 'storm' causes a systemic T cell response in the patient, which is associated with the critical condition of COVID-19 patients. Another highly inflammatory form of programmed eukaryotic cell death, called pyroptosis, is thought to occur with cytopathic viruses, like SARCoV-2, a process that is commonly associated with intracellular pathogens and can be induced by mast cells (MC) [9].

There are two spike subunits on the envelope of SARS-CoV-2, S1 and S2, where S1 binds to the Angiotensin-Converting Enzyme (ACE-2), a receptor on the host, while S2 binds to the cell surface membrane. The nasal mucosa and pharyngeal/oral cavity have ACE2 receptors but it is also found frequently on type II alveolar cells, in the lungs. ACE-2 is the functional receptor for the virus and the first step in SARSCoV-2 pathogenesis [10]. Indeed, the ability of SARCoV-2 to enter host cells is very dependant on the activity of pulmonary ACE-2 $[11,12]$. ACE-2 is a ubiquitous receptor found on many cells, most abundantly in kidney, duodenum, colon, gallbladder and testes. The heart, eye, liver, bladder, pancreas, brain and placenta also express ACE2 receptors. Oral expression of the ACE2 receptor RNA is high [13]. 
Type II Transmembrane Serine Proteases (TMPRSS2) are host transmembrane proteases that augment SARS-S host cell entry, by using two different mechanisms, allowing the virus to enter the cells. TMPRSS2 activates the spike protein causing an irreversible conformational change of the glycoprotein S2 subunit, thus enabling the virus to fuse to the cell membrane [14].

Different immunopathology and responses to the virus are apparent, from asymptomatic to severe respiratory distress, organ failure and ultimately death. Some significant clinical features of patients with corona viruses include, dyspnea, hypoxemia, acute respiratory distress, lymphopenia, and cytokine release syndrome, suggesting that disruption in the homeostasis of the immune system could play an important role in the development of COVID-19 viral pneumonia $[14,15]$. Several factors appear to determine the disease outcome including, genetics (such as HLA or cytokine genes), age, gender, neuroendocrine-immune regulation, a patient's current physical and nutritional status, and ethnicity $[16,17]$. Several pro-inflammatory mediators are expressed, such as, cytokines and histamine, which will be discussed further in this paper. Other mediators that impact the immune system are bradykinin, prostaglandins, and leukotriene but these are beyond the remit of this review [18].

This review addresses a collection of different connected immune and environmental factors that have culminated in an intriguing landscape of the SARSCoV-2 infection, including the combined interrelated associations of histamine, MCs, cytokines, novel lymphocytes (Th17), Ultra Violet (UV), Vitamin D status and some other susceptibilities related to severe disease outcome, including age and ethnicity.

\section{Immunology Overview}

Viral infections clearly require precise regulation of the innate immunity by inflammatory immune mechanisms but it is clear that over-activation of these processes can cause immunopathology with further complications to infected patients.

Resident innate immune cells respond to the presence of the virus and present epitopes to the adaptive immune system. Humoral and cellular immunity are stimulated by the viral antigen presentation to virus-specific $\mathrm{B}$ and $\mathrm{T}$ cells by antigen presenting cells (APCs) cells [19].

As previously mentioned, the virus invades the respiratory mucosa where there is an initial asymptomatic state, when SARCoV-2 probably binds to the epithelial cells in the cavity. In vitro data suggests that ciliated cells are the primary ones to be infected, however these cells have a low level of ACE2 expression, so details of this mechanism need to be confirmed. The highest ACE2 expression is detected in the nasal cavity with decreasing expression descending down to the lower respiratory tract measured using high-sensitivity RNA in situ mapping. This mapping correlated with the gradient of SARSCoV-2 infection and was highest proximately but lowest distally, along the pulmonary epithelial cultures [20].

Interestingly, children do not seem to be severely affected by COVID-19 and it is speculated that this is because they have higher levels of ACE2 and greater numbers of lymphocytes, due to higher incidences of viral infections. Lymphocytes, ACE2 and the regular occurrence of viral infections are depleted with increasing age [21].

As the virus migrates and proliferates, it invades the type II alveolar pneumocytes, initiating a cascade of events, resulting in the viral RNA entering the host cell cytoplasm. The activation of the resident innate immune cells establishes a chemokine-controlled chemotactic pathway for many other immune cells and facilitates the movement of fluid through the fenestrated epithelium, which is associated with the critical condition of pneumonia in COVID-19 patients [13].

\section{Mast Cells, Histamines and Histamine Receptors}

There are several new emerging roles of mast cells (MCs) in host defence. MCs originate from haematopoietic progenitor cells, being granulocytes derived from myeloid stem cells, which circulate in an inactivated form before becoming resident in mucosa. MCs can be associated with neuro-immune systems and are also important in wound healing releasing factors, promoting the recruitment of leukocytes, platelet activation and fibrogenic processes [22,23].

As members of the innate immune system, MCs are highly effective sentinel cells. They are located in places like skin, lung, and intestinal mucosa and are closely in contact with the outside world. MCs also have an immediate activated response to parasite infections and the antigens involved in allergies. In the case of parasites and allergens, these long-lived MCs defend against parasites, while maintaining an immune protection on the physical barriers in the body [24].

Due to the location of MCs and their plasticity, along with the many mediators that they produce, they have an immune modulator and effector role that links and orchestrate the innate and adaptive immune responses against pathogens [24,25]. After recognising a pathogen, MCs alter the inflammatory environment by instantly releasing a host of proinflammatory mediators that then mobilise other immune cells at the site of infection [26]. As innate immune cells, MCs are phenotypes that are tuned by cytokines and other micro-environmental stimuli [27].

An in vivo experiment with rats, determined that IL-3 was involved in the recruitment of MCs. Another in vivo experiment determined a wide variety of amino acids that activated MCs via the protein receptor, MRGPRX2, a non-selective receptor. This receptor is stimulated by a wide variety of positively charged, aromatic/aliphatic amino acids and peptides rich in helical structure. Peptides that caused vasoconstriction and bound to MRGPRX2 were Sarafotoxin $B$ venom and the microbial cathelicidin-associated LL-37. There were differential effects, dependant on the target tissue and time of exposure to the chemoattractant $[28,29]$. Other mediators that stimulate MCs and trigger degranulation, proliferation and release of mediators include, IgG, complement components, TLR ligands, neuropeptides, cytokines, chemokines as well as other inflammatory products [28-30].

Migration and differentiation are also stimulated by these inflammatory components. Thus the true versatility of MCs is recognised when they respond to a wide repertoire of different stimuli and not just Age involvement [22,31].

The allergic response is mediated by a cross linking of FceR1 with immunoglobulin E (IgE), which results in the degranulation of the MCs. This particular linkage is used in MC detection by applying high infinity IgE or staining the MC granules with toluene blue may be used to characterise the cells [22,32] (Figure 1).

Indeed, there are a wide variety of receptors expressed on the surface of MCs that enable their activation by several different ligands, such as, endogenous cytokines, IgE, TLR ligands and IgG immune complexes. Inflamed tissue contains many of these ligands and the Mas-related G-protein coupled receptor member X2 (MRGPRX2). The MC receptor is an important non-IgE dependant pathway in the activation of MCs, by peptide stimuli, previously described $[27,28]$. 


\section{Possible mast cell activation by COVID 19}

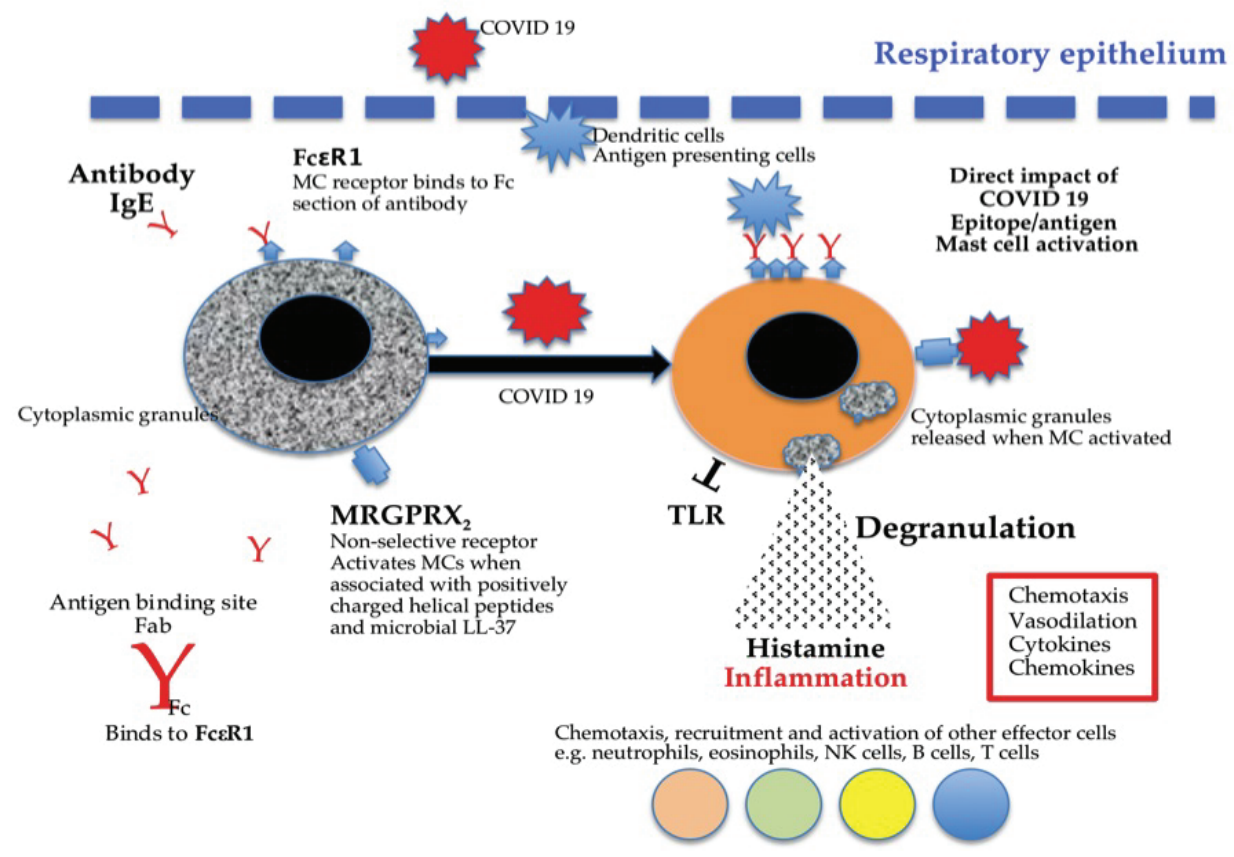

Figure 1: A simplified diagram of mast cell activation and their receptors and activators that cause the degranulation of proinflammatory mediators (chymase, tryptase, histamine and cytokines), with possible reference to COVID 19 activating mast cells.

A number of mediators including, chymase, tryptase, histamine with other cytokines and chemokines are released, dependent on the route of activation [22,32].

The activated $\mathrm{MC}$ response results in the release of a broad spectrum of proinflammatory mediators, proteolytic enzymes and chemotactic factors that attract other immune cells. Proteolytic enzymes induce rapid inflammation and tissue remodelling [22,31,33].

Although the pathogenesis of RA is not fully understood, with regard to MCs, joint destruction and tissue remodelling possibly occurs due to the MC recruitment of neutrophils and monocytes that facilitate the damage of joint related cartilage when they activate osteoclasts. Histamine is a mediator that is involved in the activation of osteoclasts. Drugs, such as, dexamethasone are successful in reducing this process in rheumatoid arthritis by inhibiting mast cell activation and found to improve patients severely affected by COVID-19, reducing deaths by one third [33,34].

In the case of COVID-19 infection, the protective barriers of MCs are located at the interface between host and the environment; for example, the SARCoV-2 virus activates the MCs of the submucosa in the respiratory tract, triggering MCs to release histamine and protease. They later activate a cascade of cytokines, including IL-1 and IL-33 [22]. Histamine, in addition to affecting vascular and bronchial responses, is increasingly identified with modulation of these immune responses, including a variety of lymphocytes, such as $\mathrm{T}$ cells. These will be discussed in more detail later [32,33]. Early attempts of therapy for severely affected COVID-19 patients involved targeting the pro-inflammatory processes with anti-inflammatory drugs [34]. Interestingly, lower levels of MC-derived granulocytes are observed in the severe COVID-19 group than those mildly infected, [33-35] raising further questions about MC involvement in COVID-19.
Clearly, in the case of allergies, the immune response involving inappropriate degranulation and inflammation is detrimental and can cause asthma, even promote anaphylaxis and it seems that COVID-19 may have a similar pathogenesis in severe cases [32]. The MCs are rich in granules of histamine and heparin, all-important in the fenestration of epithelium to enable other immune cells, such as, lymphocytes to migrate to the source of supposed infection. Other mediators of the immune response from MC granules are leukotrienes (causing shortness of breath), prostaglandins, tryptase, interleukins, heparin and TNF-alpha [35-37].

MCs promote anti-inflammatory mediators as well as proinflammatory processes and they can act as antigen presenting cells (APCs) that express a large array of co-stimulatory molecules. MCs are able to tolerate the introduction of some antigens without eliciting an inflammatory immune response in certain sites of the human body and are described as having immune privilege to tissues with T-regulatory cells as well as being essential elements in fibrotic conditions [38,39].

Thus MCs mediate the bronchoconstriction associated with viral infections and are a major source of inflammatory cytokines, implicated in autoimmune pathology. Thus, MCs contribute to coronavirus-associated hyper-inflammation [40].

As previously established, in immune and allergic responses, MCs are a potential source of chemokines and cytokines that are important in inflammation. However, Toll-like receptors (TLR) and IL-1 also activate MCs [41]. IL-1 is also an important cytokine in the immune response that activates the release of inflammatory chemical mediators from MCs, causing lung and tissue inflammation, fever and fibrosis [41]. Over expression of IL-1 is typical in SARSCoV-2 infection 
and contributes to the adverse proinflammatory pathology during COVID-19 infection [38-40,42].

Vitamin D is a 'Golden Thread' running through and connecting the 'fabric' of all of these immune mechanisms and factors discussed in this review. It is understood that Vitamin D contributes to the stabilisation of MC activation and homeostasis, reducing hyperinflammatory reactions [43].

As already mentioned, histamine (2-[3H-imidazol-4-yl]ethanamine) is an important substance released from activated MCs and is involved in the chemical events that occur during inflammatory conditions of vasodilation and increased vascular permeability, during local immune responses [18]. Typical symptoms experienced during allergy are flushing, itching, diarrhoea and hypotension, all mediated by histamine. These symptoms are caused by this vasoactive biogenic amine, which has the dichotomous nature of promoting inflammatory and regulatory responses, while contributing to the pathological processes that promote many vascular and tissue changes and has a high chemo attractant activity $[18,44]$.

MCs expressing histamine are located in the nose, mouth, feet, and many internal body surfaces, such as, blood vessels. The lungs are major sites for histamine control, where it can be responsible for hyper-responsiveness and contribution to pulmonary remodelling. It is not completely understood but this depends upon the histamine receptor and cell type involved $[18,45]$.

Many cell types of the innate and adaptive human immune system are influenced by histamine $[46,47]$. Th1 and Th2 balance is directly regulated by histamine [46]. The stimulus of histamine also induces the expression of IL-17 in Th17 cells and activation of lymphocytes in some inflammatory conditions $[18,47]$.

It is important to include a discussion about histamine receptors when describing the influences of histamine in an immune reaction. The pleiotropic effects of histamine are mediated by $4 \mathrm{G}$-protein coupled receptors (H1-4) [48]. Conformations of these receptors coexist in equilibrium and are stabilized in their active form by agonists. The expression of these receptors differs according to the differentiation of the cell, which are influenced by the microenvironment $[48,49]$.

Returning to Vitamin D involvement, Vitamin D has an antihistaminic activity by inhibiting $\mathrm{H} 1$ and histamine release in experimental animal studies. This is thought to explain the antiinflammatory effects of Vitamin D in the lung inflammation in asthma patients through reduced IgE mediated histamine release [50]. The Cochrane Review's lead author, Professor Adrian Martineau from the Asthma UK Centre for Applied Research, Queen Mary University of London, said, "We found that taking a Vitamin D supplement in addition to standard asthma treatment significantly reduced the risk of severe asthma attacks, without causing side effects" [51].

The histamine receptor effects can also be determined by genetics but also, interestingly, by gut micro biota, aging, gender and other diseases. Gut bacteria itself produces histamine [50-52].

HR1 is important in promoting Th1 responses, whereas HR2 promotes Th2 profiles and allergic lung inflammation is associated with the predominant recruitment of Th2 cells. $\mathrm{T}$ cell responses will be discussed later in more detail; however, $\mathrm{H} 2$ activates $\mathrm{Th} 2$ promoted humoral immunity with increased IL-10 and promotion of $\operatorname{IgE}$ production, increasing the humoral response to infection [50].

Activation of HR1 and HR2 are associated with MC and basophilmediated disorders, such as, allergy. HR1 antagonism is important in reducing inflammation in asthma whereas $\mathrm{H} 2$ deficiency is known to worsen lung inflammation [49].

Curiously, the aging process is a factor that impairs expression or activity of HRs and enzymes HDC and DAO may contribute to the progression of allergic reactions and various neurodegenerative disorders. Chronic itching occurs in the elderly as changes in immunology and physiology change with age [22]; in fact, the older generation is more susceptible to the hyper-inflammatory lung conditions and ARD in COVID-19 [53].

It was discussed previously that MCs are present in the protective barriers of the submucosa in the respiratory tract and are activated by the virus to release histamine and protease while later activating IL-1 and IL-33. As mentioned earlier, histamine modulates vascular and immune responses, including $\mathrm{T}$ cells. During a viral infection, histamine binds to $\mathrm{H} 1$ of human lung macrophages and induces proinflammatory cytokines with exocytosis of IL-6 in human lung macrophages and $\beta$-glucuronidase [45,46,54].

H4R receptor signalling, not only affects Th1/Th2 differentiation, eosinophil, MC chemotaxis and IL-6 expression, but also increases IL-17 secretion by Th17 cells as well as regulatory T cell recruitment, while suppressing IL-12p70 of dendritic cells [55].

\section{Cytokines, T Cell Differentiation and COVID-19}

The cytokine 'soup' that is induced by the presence of COVID-19 evokes many cytokine options, however, this review will focus primarily on the effects of IL-12 and IL-17, where mast cells play a significant role in the production of IL-12 in host defence and a crucial source of this cytokine.

IL-12 is a key signal of the innate immune system, that acts as a bridge between innate and acquired immunity, and thus, plays a significant role in the development of antiviral immune responses. Previously, IL-12 was also known as Natural Killer Cell Stimulatory Factor (NKSF2) and as T cell stimulating factor (TSF) [56,57].

The functional IL-12 heterodimer is a proinflammatory cytokine with immune-regulatory function [58-60]. Its production is important in the generation of cell-mediated immunity against many intracellular pathogens, including bacteria, fungi, protozoans and viruses [61,62]. The cytokine can, however, enhance or inhibit humoral immunity, depending on the Ig isotype and the stimulus to antibody formation. IgG2a,b and IgG3 responses are associated with Th1 responses and Th2 responses are associated with $\operatorname{IgG} 1$ antibodies, which are suppressed by IL-12 [61].

Microbial lipoproteins are potent stimulators of IL-12 by human macrophages, mediated by TLR and scavenger receptors. Several lipoproteins are reported to stimulate TLR dependent production of Nitric Oxide Synthase (NOS) and the production of nitric oxide is important in antimicrobial activity. The innate immune response involving IL-12 signalling requires type 2 nitric oxide synthase [62,63].

IL-12 induced the synthesis of IFN $\gamma$ IL-2 and TNFa [56,57]. However in contrast, IL-10 has been shown to inhibit lymphocyte production of IFN $\gamma$ by suppressing IL-12 synthesis in accessory cells [58]. Thus, the IL-12 viral immune response is involved in enhancing the cytotoxic response and the fact that Th1 driven responses are important for viral clearance suggest that IL-12 is an important factor in the disease. Polymorphisms in the IL-12B (p40) gene were associated with different outcomes to infection in HCV patients [64-66]. Indeed, deficiency of IL-12 has been associated with recurrent episodes of pneumonia with sepsis and other infections in the absence of fevers. 
As a viral comparison of HCV to COVID-19, IL-12 and IFN $\gamma$ levels are lower in patients more viraemic than in patients who spontaneously cleared HCV [67]. It was hypothesized that type 1 IFN protective responses may reinforce innate antiviral immunity to SARSCoV-2 and that the adequate status of Vitamin D has an immuno modulatory activity that helps to provide an early, innate type 1 IFN antiviral protection [68].

Although APCs produce most of the cytokine, T cells also produce IL-12 [60]. An important property of IL-12 is to induce the production of large amounts of IFN $\gamma$ from resting and activated T and NK cells [69]. The most distinctive role of IL-12 is to regulate the balance between Th1 and Th2 cells [61]. Allogeneic cytotoxic lymphocyte responses are promoted by IL-12 in peripheral cells of the Th- 1 cell differentiation and therefore able to destroy virally infected cells during a COVID-19 infection [70,71].

Another cytokine to be considered in this review is IL-17 as a key cytokine linking $\mathrm{T}$ cell activation to the mobilisation and activation of neutrophils and MCs and their degranulation [72].

IL-17 is expressed from Th17 cells, MCs and neutrophils when stimulated by IL-23, and activates several signalling cascades, inducing chemoattractant chemokines that recruit neutrophils and monocytes, to the site of injury or infection. Its activation has been observed in some autoimmune disorders [73,74]. IL-17A expression is up regulated by Th17 cells at sites of inflammation in several autoimmune diseases. IL-17 is a pleiotropic proinflammatory cytokine, where the one gene exhibits two or more phenotypic traits [75].

When considering the T cell response to COVID-19 and the T-cell differentiation, other pathways must be considered in addition to Th1 and Th2 driven responses, such as Th17 differentiation [76]. Both B and $\mathrm{T}$ cell specific SARS-CoV-2 are detected in patient blood around one week after initial infection symptoms [77,78]. In the H1N1 pandemic, severe disease with respiratory involvement were marked by an early secretion of Th17 and Th1 cytokines. These T cell responses are most important, as host defence reactions, to clear pathogens but they are also involved in tissue inflammation in allergic and autoimmune diseases. The ratio of Th1/Th17 has been suggested as an indicator to determine the severity of disease in COVID-19 patients [77,78].

Meta-analysis and systematic reviews of studies that investigated the lymphocyte count, on admission to intensive care units, showed that lymphopenia was significantly associated with poor patient outcomes in COVID-19 patients. This could be used as a marker, especially in younger patients, as an indication of severity of disease. Lymphopenia was defined as less that $1100 / \mu \mathrm{L}$ associated with a threefold risk of poor outcome $[17,42,78,79]$. One hypothesis to explain this phenomenon is that lymphocytes express ACE2 and that they themselves may be the targets for SARSCoV-2, and that an increase in proinflammatory cytokines, such as, IL-6, in COVID-19 may reduce lymphocytes further [68]. This level of $\mathrm{T}$ cell exhaustion and reduced functional diversity in peripheral blood may be an indication of severe progression in COVID-19 patients $[79,80]$.

Although T-cell levels are important in the viral resolution, it is the differentiation of uncommitted $\mathrm{T}$ cells, during the induction of a cytotoxic antiviral host response, characterized by the secretion of lymphokines associated with cell-mediated immunity, which is extremely relevant. A strong Th1 CD4+ response is also thought to be essential for spontaneous viral clearance and this is facilitated by the expression of IL-12 from macrophages and dendritic cells. IL-12 mediates some physiological activities by acting as a potent inducer of IFN $\gamma$ secretion by Th1 and natural killer cells, both of which are deemed to be extremely important in the clearance of viraemia, generally. COVID-19 patients that resolve the virus have improved cytotoxic $\mathrm{T}$ cell numbers, indicating their importance in better disease outcomes [71].

The production of IL-12 is vital for much viral clearance, initiating Th1 responses; however, the unregulated and on-going IL12 production can result in infection-induced immunopathology and further tissue damage. When IL-12 production from dendritic cells by microbial products was inhibited, the infection-induced immunopathology was reduced [81].

To summarise, the adverse effects of aberrant Th1/Th2 cell immune responses are responsible for the pathogenesis of several diseases. Hypersensitivity-related Th2 responses are linked to a humoral (antibody) response and the development of atopy, whereas Th1 differentiation is often associated with the pathology of certain autoimmune processes in a cytotoxic response. The balance of the cytokines that drives a predominantly Th2 humoral response is one of increased IL-10 expression rather than IL-12 expression [82]. Returning our attention to Vitamin $\mathrm{D}$, it seems that the hormone also influences the dendritic and other cell expression of IL-12 in inflammatory diseases [83].

As described previously, histamine is an important factor in the Th1 and Th2 balance in the immune response to virus. Insufficient Th1 cytotoxic responses can result in chronic viral infection [73]. Further to the $\mathrm{T}$ cell balance, the ratio of neutrophils (granulocytes) to lymphocytes has been sited as an indication of subclinical inflammation and may be helpful as a tool to screen for the severity of the COVID-19 infection outcome [78].

Th17 cells are a subset of CD4+ T helper cells that produce IL17. Th17 has an important role in the human immune system in the host defence against infection but it is also considered to be a key element in the development of autoimmune inflammatory disorders. In a general sense, during persistent viral infections associated with chronic conditions, IL-17-producing Th17 cells are implicated in the pathogenesis of these conditions. Th17 cells also enhance viral persistence and inhibit $\mathrm{T}$ cell cytotoxicity to the virus in a model of chronic virus infection $[55,84,85]$.

In the case of HIV infection Th17 cells can be reservoirs of the virus, in patients taking antiretroviral therapy, contributing to the latency of HIV infection [86]. It is suggested that this may occur in COVID-19 patients with prolonged unresolved viral infection. Also, lymphocytes within the oral mucosa express the ACE2 viral receptor for COVID-19 and it has been suggested that this may be a possible cause of the lymphopenia observed in severely affected COVID-19 patients, where there may be virus-induced apoptosis of T cells [86,87].

IL-17 was found to mediate acute lung injury in the 2009 influenza A (H1N1) pandemic, whereas, IL-21 encourages Th17 differentiation and proliferation [88]. Th17 has immunosuppressive properties that decrease the antiviral response to some infections, such as HIV, where the loss of Th17 can result in an imbalance of Th17 and Treg cells [89].

A high number of CCR6+ Th17 cells were observed in the cytokine storm in a severely affected COVID-19 patient supporting the hypothesis that Th17 cells are important factors of the cytokine storm in the disease [90]. Elevated Th17 cells and enhanced IL-17 pathways were also a factor in patients with MERS-CoV and SARS-CoV. The H1N1 infection in mice caused acute lung injury was induced by IL17 expression [90]. Promisingly, there are some anti Th17 and IL-17 blockades using antibody drugs that are currently being trialled in 
China, ixekizumab, a drug developed for the treatment of psoriasis $[73,74]$.

Returning to the effects of Vitamin D, it has been demonstrated that the loss of Th17 differentiation can result in chronic infections and that excessive differentiation and expansion of Th17 can be inhibited by Vitamin $\mathrm{D}$, as evidenced in young asthmatic children [51,91,92]. Indeed, human memory Th17 cell populations change into antiinflammatory cells with regulatory capacity upon exposure to active Vitamin D metabolite $(1,25(\mathrm{OH}) 2 \mathrm{D} 3)$ as Th17 cells are not always pathogenic unless exposed to IL-23 (Figure 2) [93,94].

Vitamin D is considered to supress IL-17A production in T cells in some conditions (rheumatoid arthritis, multiple sclerosis, colitis) and IL-6 and IL-22 expression may also be down regulated from naive and memory CD4+T cells [91].

\section{Vitamin D and UV Index}

Several brief references to Vitamin D have already been made with regard to its influence on immune responses. More detailed information will be discussed about the significant impact of this hormone in this section. 1,25-DihydroxyVitamin $\mathrm{D}_{3}\left(1,25(\mathrm{OH})_{2} \mathrm{D}_{3}\right)$ or calcitriol is the active form of Vitamin $\mathrm{D}$ and has emerged as a direct regulator of immune system function in humans [93]. Important mechanisms involving the human immune system are mediated through the Vitamin D receptor (VDR) via the non-canonical processes of Vitamin $\mathrm{D}$ binding to the receptor. This receptor is expressed by macrophages, dendritic cells and activated T cells [93].
The non-skeletal effects of Vitamin D have been of increasing interest with regard to its association with several diseases and, in particular, its role in regulating the immune system at the cellular level. Vitamin D has a physiological role in immunomodulation, targeting several cells of the immune system and is a key factor linking innate and adaptive immunity, both being compromised with Vitamin $\mathrm{D}$ deficiency [94]. There is considerable evidence from research literature that hypovitaminosis $\mathrm{D}$ is associated with several immune and autoimmune disorders in addition to its classical association with osteomalacia (Rickets) [94].

A number of immune cells have the cellular ability themselves to convert 25-hydroxyVitamin $\mathrm{D}$ to its active state, $1 \alpha, 25(\mathrm{OH})_{2} \mathrm{D}_{3}$ promoting responses to pathogens in macrophages. Another antimicrobial response is in regulating the maturation of antigenpresenting dendritic cells and this pathway controls T-lymphocyte function. T cells also respond directly to the activated form of Vitamin D through Vitamin D receptors (VDR). Cellular interplay, during an immune response, is highly complex but it is clear that $1 \alpha, 25(\mathrm{OH})_{2} \mathrm{D}_{3}$ influences TNFa, and IFN $\gamma$ expression from different cell types, particularly from $\mathrm{T}$ cells. The complex picture for APCs, such as, dendritic cells and monocytes, is not completely understood [95].

Several epidemiological studies link higher susceptibility to immune-mediated disorders with Vitamin D deficiency. Other studies suggest that the vitamin has a modulatory role in the inflammatory response of cells of the monocyte/macrophage lineage, which is also modulated by transforming growth factor- $\beta$ (TGF- $\beta$ ). Vitamin

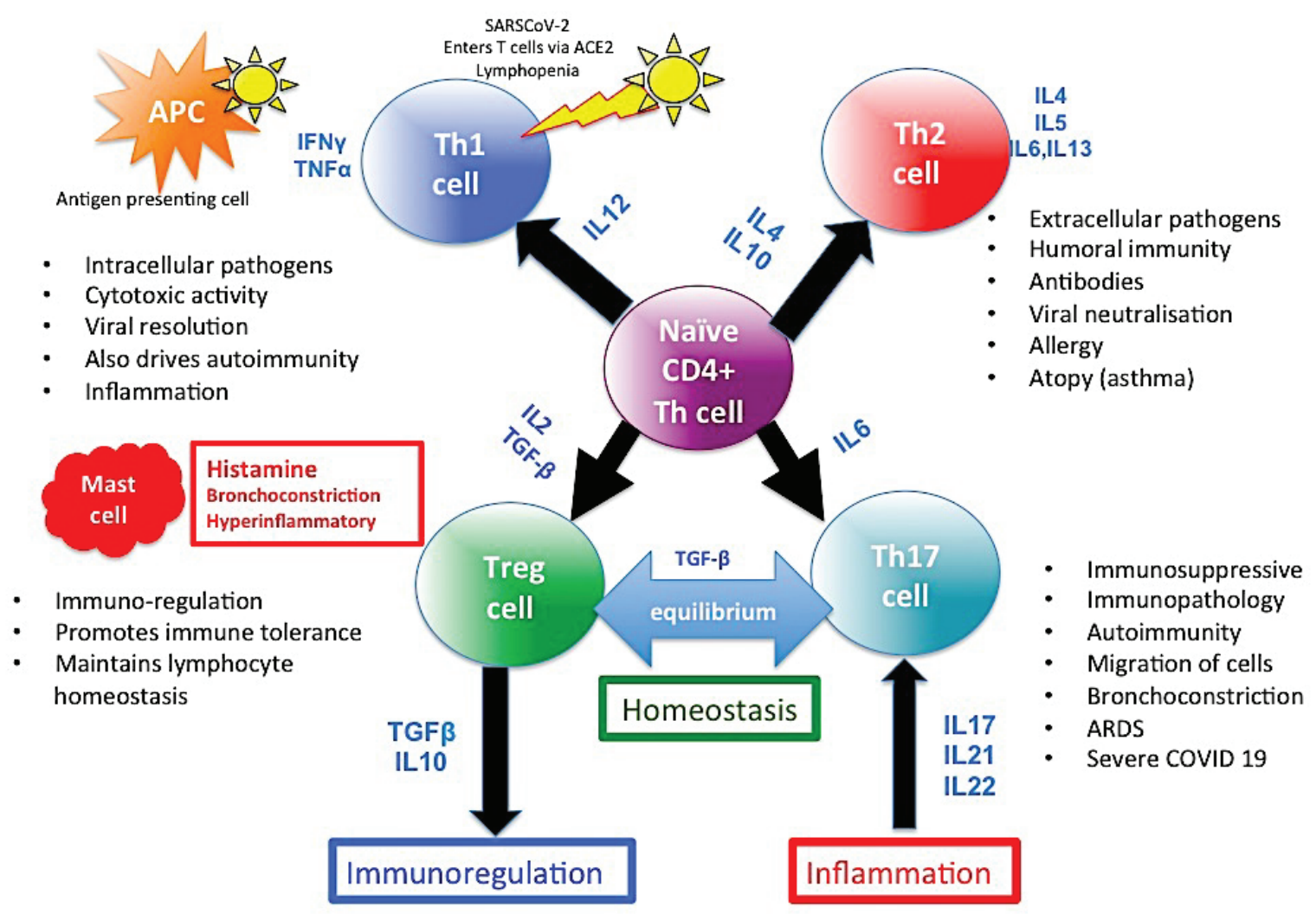

Figure 2: Shows the differentiation, mediators and outcomes of SARS CoV-2 infection. Severely affected patients have higher levels of IL17 and Th17 that are not in balance by Treg cells causing Hyperinflammation. 
D regulates the leukotrienes, which are lymphocyte associated eicosanoid inflammatory mediators, biologically active compounds that cause shortness of breath as experienced in inflammatory diseases. This Vitamin D hormone also regulates the prostaglandins that are responsible for pain, brain fog, cramping and flushing in immune responses. These arachidonic acid-derived eicosanoids play an important role in inflammatory conditions and Vitamin D is shown to inhibit prostaglandin production in lung tissue [94-97].

Another immunomodulatory function of the cells of the immune system is that they express Vitamin D-activating enzymes, which enables the conversion of Vitamin D into its active form $[98,99]$.

In addition to the role of Th17, as discussed previously, Vitamin D is involved in pulmonary function in inflammatory pulmonary disease and as such also affected by hypovitaminosis D. In fact, when Vitamin $\mathrm{D}$ was supplemented to patients, with mild to moderate asthma, in a clinical trial, it was concluded that the vitamin was able to improve pulmonary function (FEV1) in those patients [91-93].

The vitamin has also been shown to alleviate lipopolysaccharideinduced acute lung injury (gram-negative bacilli glycoprotein) in Acute Respiratory Distress Syndrome (ARDS), as sometimes observed in severely affected COVID-19 patients with increased alveolar epithelial and pulmonary micro vascular endothelial permeability, pulmonary oedema and fibrosis. This is also through RAS [100].

UV exposure is directly related to the global UV index, which is also associated with Vitamin D synthesis in skin. The vitamin then undergoes activation via a binding protein in the liver and kidney. Higher levels of melanin in melanocytes inhibit Vitamin D synthesis and the currently low UV index in the UK may influence the demographic findings of UK healthcare workers from black, Asian and mixed ethnicity (BAME) groups that have succumbed to the virus. The higher melanin content of skin affects serum 1,25-Dihydroxyvitamin synthesis and status, particularly in regions with a low UV index. Low levels of Vitamin D are associated inversely, with an increase in blood pressure in these individuals [101-103].

Vitamin D insufficiency or deficiency is associated with regulation of insulin secretion and glucose levels. Deficiency also causes the inflammation associated with adipose metabolic diseases, such as obesity, multiple sclerosis, diabetes, and fatty liver. Metabolic conditions are also sited as causes for severe complications arising from patients with COVID-19 [104,105].

There are a number of population differences for gene variants within multiple gene loci, many of which are population-specific observed Vitamin D variants, some related to geographic location or ethnicity between European, East-Asian, and Sub-Saharan African ancestry [106].

The Vitamin D receptor is expressed in adipose tissue and the vitamin itself is stored there. It is suggested that Vitamin D exerts anti-adipogenic influence on some pre-adipocytes and regulates the expression of adipocyte transcription factors, such as, PPAR $\gamma, \mathrm{C} /$ $\mathrm{EBP} \alpha$, and LPL. Obesity is a recognized factor associated with more severe disease and death from COVID-19 infection [100].

It is poignant at this venture to mention Vitamin D resistance is a condition that occurs when the VDR is not functional and it results in high renin hypertension, cardiac hypertrophy and thrombogenesis. Polymorphisms in the receptor genes also alter functional Vitamin $\mathrm{D}$ levels and can influence disease, but are not necessarily factors differentiating them between different ethnic groups [107-109].
Located on chromosome 12q13.11 in humans, the VDR gene consists of eleven exons. Several polymorphisms of the VDR gene have been identified [109].

The amount of UV exposure is related to the global UV index thus associated with Vitamin D synthesis in skin. Vitamin D is synthesized in the skin from its precursor, 7-dehydrocholesterol and requires sunlight or UV irradiation. The vitamin's activation occurs via a binding protein in the liver and kidney [110].

Aside from Vitamin D synthesis, the influence of light-based technology can be used to prevent and treat viral infections and is indicated as a method to decontaminate human environments that have been exposed to biological agents, without causing undue harm to host tissue [111-113].

There are apparent seasonal differences in the recent global spread of COVID-19 spread, with the possibility of viral transmission throughout the world, particularly as a result of international travel and globalisation. It is observed that low temperature and low UV index often correlates with peaks of viral activity in the northern hemisphere, having an apparent seasonal influence on COVID-19 spread, partly explained by the low atmospheric UV levels in those regions. UV levels may be a factor involved in other seasonal epidemics [114], indeed, the MERS virus was efficiently inactivated by UV A light in human platelet concentrates $[115,116]$.

Germicidal UV (UVC) light from monochromatic or polychromatic light sources destroys many viruses and research data suggests that UVC has a high selectivity over host mammalian cells and tissues. Further, Near Infra Red (NIR) has been shown to cause damage to the protein coat of a virus or bacteria, thus inactivating it using NIR femtosecond laser. This process targets the mechanical or vibrational properties of microorganisms $[117,118]$.

Clearly, consideration should be made for individuals as UV light is a mutagen to microbes and humans alike and people who are susceptible to UV DNA damage (e.g. P53 mutations, Li-Fraumeni) should be warned about exposure. If levels are well within safe values, similar to safe levels of natural sunlight exposure for unaffected individuals, then this is a strategy worth considering in countries affected by the COVID 19 with a low UV index [119].

\section{ACE2, COVID-19 and the Renin/Angiotensin System (RAS)}

It was explained earlier that SARCoV-2 virus attaches to ACE-2 in respiratory cells, an important receptor for the renin/angiotensin system (RAS), described as a regulator of blood pressure by a hormonal cascade. This cascade regulates electrolyte and body fluid volume homeostasis, controlling blood pressure as well as regulating systemic vascular resistance.

Evidence is increasing for the role of Vitamin D, 1,25-dihydroxyVitamin $\mathrm{D}_{3}$ as a negative endocrine regulator of Renin Angiotensin System (RAS) and normal Vitamin D status can lower the activity of RAS via the transcriptional suppression of renin expression [120]. This has also been suggested as an explanation for the higher incidence of hypertension in BAME patients, due to reduced Vitamin D synthesis in these patients, as described earlier [101-103].

ACE2 degrades angiotensin II (AngII) to generate angiotensin 1-7 in the ACE2/angiotensin 1-7/mas receptor axis and counteracts the excessively activated ACE/AngII/AT1R axis observed in hypertension, cardiac hypertrophy, heart failure, and other cardiovascular diseases. Hypertension is recognised as a major risk for COVID-19 patients, 
increasing the risk of death significantly. Vitamin D inhibits hypertension by activating the ACE2/angiotensin-(1-7) axis, thereby exerting protective effects against COVID-19. The activity and structure of RAS changes with age, where an age related functional decline occurs. Physical exercise is demonstrated to improve the RAS system, in addition to antihypertensive drugs, that improve cardiovascular conditions but no pharmacological intervention is completely effective on RAS [121].

ACE inhibition is established as an effective therapy in the treatment of cardiovascular disease, where angiotensin II is shown to exacerbate the hypertension, chronic heart failure, and atherosclerosis, whereas nitric oxide exerts positive effects. ACE2 regulates the RAS that is so important in maintaining blood pressure and fluid/electrolyte balance [13].

There is evidence that the MC enzyme chymase is able to generate Ang II independently of the activity of ACE, circumventing the functional protection otherwise provided by an ACE inhibitor under non-inflammatory conditions. However, when Angiotensin Receptor Blockers (ARB) is administered, stimulated MCs lose much of their microcirculatory destabilising potential and lessons may be learnt from this associated with the COVID-19 pandemic [122,123]. Common ARBs may exert anti-inflammatory mechanisms by modulating the immune system directly [124]. SARSCoV2 infection in mice greatly reduced lung ACE2 protein levels, depending on the degree of viral replication [125].

There has been some discussion about the comorbidities, including cardiovascular disease and diabetes, which often qualify for angiotensin inhibitor (ACEI) therapy that significantly increases mRNA expression of cardiac ACE2. Thus, on this basis, the treatment may exacerbate the severe course of COVID-19 infection. The European Society of Cardiology, now express that ACEIs and ARBs are safe and should be continued and prescribed according to established guidelines during COVID-19 infection. Indeed, ARBs have recently been suggested as a useful strategy to inhibit COVID-19 infection [126].

In a retrospective study in Hubei province in China, COVID-19 patients were admitted to 9 hospitals in a multi-centre study.1128 hospitalised adult patients, positive for COVID 19, with hypertension were included in the study. There were 188 patients taking ACEI/ARB and 940 not taking ACEI/ARB with a median age of 64 years. ACEI/ ARB was associated with lower risk of all-cause mortality, compared with the non-ACEI/ARB group (3.7\% vs. 9.8\%; $\mathrm{P}=0.01)$ [127].

It is well understood that COVID-19 attaches to pulmonary host cells by ACE2, the angiotensin receptor, then fuses to the membrane and releases viral RNA. It is postulated that the current angiotensin blocker drugs may inhibit this mechanism of viral attachment to pulmonary cells. rhACE2 completely binds to virus S-protein, and may protect the lungs from virus attack. An improved understanding of this class of pharmaceutical intervention is required, especially in regard to its anti-inflammatory properties as it may inhibit COVID-19 virions attachment to the ACE2 receptor [128]. ACE2 expression is known to affect myeloid cell activity in both infection and malignancy, modulating both innate and adaptive immune responses, including macrophage and neutrophil function. ACE2 also limits the macrophage expression of a number of pro-inflammatory cytokines, including IL6 and TNF- $\alpha$. ACE2 is down regulated in the case of COVID-19 patients and enhances macrophage expression.

Severely affected patients are observed to show similar symptoms to Macrophage Activation Syndrome (MAS), another proinflammatory mechanism inhibited by Vitamin D. The abundant expression of
ACE2 in other organs explains the multiple organ dysfunctions with COVID-19 disease and MAS patients [129].

Further, the secosteroid hormone, Vitamin D, is a negative endocrine regulator of the RAS able to influence blood pressure and is thought to maintain the homeostasis of the cardiovascular system by suppressing RAS. Indeed, Vitamin D deficiency is thought to activate RAS leading to cardiovascular disease $[98,99]$.

Losartan or candesartan cilexetil are long lasting and effective angiotensin II type 1 receptor blockers. These drugs were well tolerated in normal cohorts when evaluated in clinical studies, with patients experiencing primary hypertension, including in the elderly. These receptor blocker drugs do not aggravate co-existing risk factors, like hyperlipidaemia or glucose intolerance [130].

Finally, there is a relationship between hypertension and hyperinflammation, where Heat Shock Proteins (HSPs) are expressed more in the circulation at times of cellular stress and correlates with RAS activity during these processes. During SARSCoV-2 infection HSP60 is released due to stress-induced expression from infected cells in circulation adding to its expression when pre-existing hypertension is a factor. The role of Vitamin D as a natural anti-inflammatory agent is evident, as less HSP circulates when there are high levels of Vitamin $\mathrm{D}[131,132]$.

\section{Conclusion}

These immune characteristics included in this discussion act in concert with both competent and dysfunctional immune responses. In the case of COVID-19, there is a 'perfect storm' that has the underlying theme of Vitamin D status, as a running theme throughout. Vitamin $\mathrm{D}$ is associated with the homeostasis and function of so many factors associated with immune responses. It is estimated that more than one billion people may be suffering from Vitamin D deficiency or insufficiency globally [131].

Vitamin $\mathrm{D}$ is important in the maturation, activation and homeostasis of MCs, their associated cytokine production, $\mathrm{T}$ cell differentiation and in RAS associated with ACE2, all of which are implicated in the pathogenesis of COVID-19. MC derived cytokines, such as IL-17, are inhibited by Vitamin D. IL-17 is expressed in Th17 cell activity, while these cells promote MC proliferation and is associated with severe infection. It is strongly considered that Th17 contributes to the cytokine storm experienced in pulmonary viral infections, such as, SARSCoV-2 infection, promoting pulmonary oedema and causing tissue damage [90].

Vitamin D is able to prevent autoimmune inflammatory diseases, by supressing Th17 cells, and as accumulating reports demonstrate, it possesses anti-inflammatory activity on Th17 cells, which maintains immunologic homeostasis. Indeed, the active form of Vitamin D directly inhibits Th17 differentiation and VDRs are elevated in Th17 cells, making them even more sensitive to the effects of the vitamin, thus decreasing viral persistence $[85,92,109]$.

MCs produce IL-17 and it is increased in patients infected with COVID-19 in intensive care, as opposed to those patients not in intensive care. Interestingly, IL-17 expression is also increased in patients with asthma and the level of cytokine expression directly correlates with the degree of bronchoconstriction and severity of the condition [51,132]. Vitamin D contributes to the repression of IL-17A expression in inflammatory CD4+ T cells [94].

Another important contribution to the cytokine storm is that of the degranulation of MCs, when activated, and the granules that they release, in particular histamine. Testing for histamine could be used 
as an indication of COVID-19 disease outcome as it is possible to measure the levels of histamine in serum and urine [133].

A recent unpublished trial, a pilot study in France, administered antihistamine to patients with COVID-19 early in presentation, and reported very positive results in the outcomes with no severe cases presenting after treatment [134].

Although there are no officially approved drugs to treat dengue disease, ketotifen is an example of a repurposed anti-inflammatory medication for MC stabilization and was found to reverse many of the responses in this disease that were due to $\mathrm{MC}$ activation, including reducing the effects of histamine [135-138].

A physician-sponsored cohort study of cetirizine and famotidine provides proof-of-concept of a safe and effective method to reduce the progression in symptom severity, by minimizing the histaminemediated cytokine storm [139]. Vitamin D is also known to stabilise MCs and further studies are required to determine its efficacy in different diseases.

There is no evidence that Vitamin D prevents COVID-19 infection or that or that its deficiency predisposes anyone to it, however, there is some evidence that Vitamin D may prevent acute respiratory infections if supplementation over weeks maintains a healthy Vitamin D status. Vitamin D deficiency is very common in the winter, particularly in the northern hemisphere. As evidence that Vitamin D deficiency may increase the severity of COVID-19, levels of C-Reactive Protein (CRP) were used as a marker for the cytokine storm and it was found that high CRP was associated with Hypovitaminosis D [140,141].

As mentioned previously, the melanin content of melanocytes may influence disease outcomes to COVID-19 infection by inhibiting Vitamin D synthesis. The UV index in the Northern Europe is very low, except for the very height of summer. This combination may possibly influence the demographics of BAME healthcare workers that have succumbed to the virus and experienced severe complications.

Further, an increased UV index may also reduce the viral load of SARSCoV-2, as the virus is sensitive to the UV radiation. The higher the UV index, the greater the depletion of the virus, however, there is no conclusive evidence for this theory so it remains to be determined. A recent statement from NICE on $29^{\text {th }}$ June 2020 for Public Health England said that Vitamin $\mathrm{D}_{3}$ (colecalciferol) and Vitamin $\mathrm{D}_{2}$ (ergocalciferol) supplements are not currently licensed for preventing or treating any infection, including COVID-19, and only licensed for the prevention of Vitamin D deficiency.

\section{Factors influencing COVID 19 patient outcome}
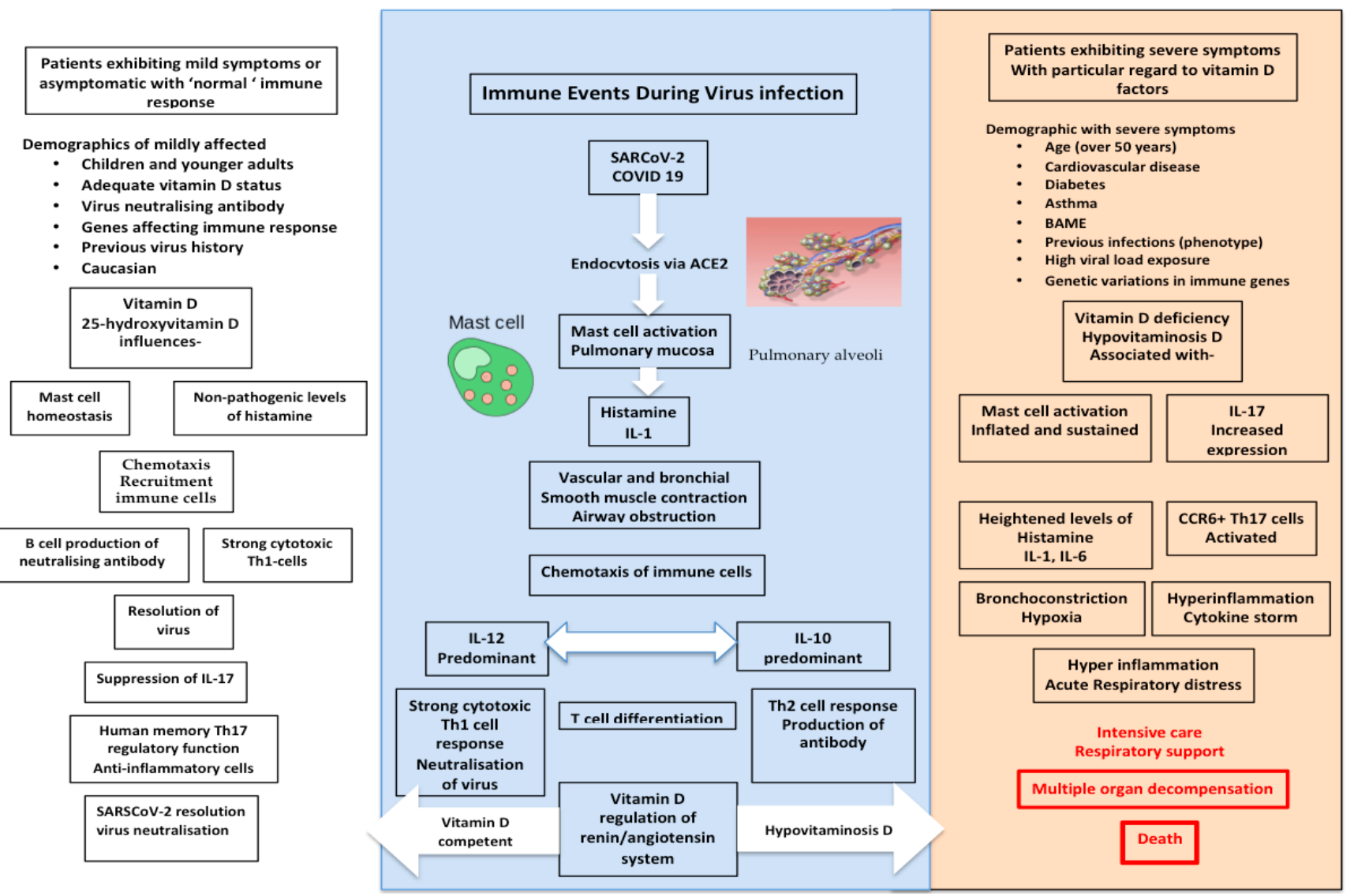

Figure 3: Factors that influence the patient outcome of COVID-19 patients demonstrating the inter-relationship between vitamin $D$, UV index, MC homeostasis, T-cell differentiation, inflammatory regulation, virus neutralisation and elements of the cytokine storm, including histamine. 
There is still so much to learn about COVID-19 during this pandemic with many further questions to ask and investigate.

Thus, in conclusion, the interaction of the SARCoV-2 virus is dependent on many factors involving viral load and viral titre as well as genetic profile, environment (UV), age, gender, nutritional status, neuroendocrine-immune regulation, and physical status. Each individual immune system results in a specific phenotypical response, some of which may be enhanced with the appropriate treatment (Figure 2). If the elements of the immune system that encounter SARSCoV-2 are the instrumentalists, then surely Vitamin D is the conductor of the orchestra in response to infection [131,140,141] (Figure 3).

A number of interventional studies report the effects of Vitamin D status and supplementation, both before and after COVID 19 infection, associating this with the severity of disease [142-150].

\section{Funding}

No financial support was received for this study.

\section{Conflicts of Interest}

The author declares that there is no conflict of interest in this study.

\section{References}

1. Wan W (2020) WHO declares a pandemic of coronavirus disease COVID-19. The Washington Post, USA.

2. Guo YR, Cao QD, Hong ZS, Tan YY, Chen SD, et al. (2020) The origin, transmission and clinical therapies on coronavirus disease 2019 (COVID-19) outbreak-an update on the status. Mil Med Res 7: 11.

3. Cyranoski D (2020) Mystery deepens over animal source of coronavirus. Nature 579: 18-19.

4. Andersen KG, Rambaut A, Lipkin WI, Holmes EC, Garry RF (2020) The proximal origin of SARS-CoV-2. Nat Med 26: 450-452.

5. Li F (2016) Structure, Function, and Evolution of Coronavirus Spike Proteins. Annu Rev Virol 3: 237-261.

6. Wrapp D, Wang N, Corbett KS, Goldsmith JA, Hsieh CL, et al. (2020) Cryo- EM structure of the 2019-nCoV spike in the perfusion conformation. Science 367: 1260-1263.

7. Xiao X, Chakraborti S, Dimitrov AS, Gramatikoff K, Dimitrov DS (2003) The SARS-CoV S glycoprotein: expression and functional characterization. Biochem Biophys Res Commun 312: 1159-1164.

8. Babcock GJ, Esshaki DJ, Thomas WD Jr, Ambrosino DM (2004) Amino acids 270 to 510 of the severe acute respiratory syndrome coronavirus spike protein are required for interaction with receptor. J Virol 78: 4552-4560.

9. Fink SL, Cookson BT (2005) Apoptosis, pyroptosis, and necrosis: mechanistic description of dead and dying eukaryotic cells. Infect Immun 73: 1907-1916.

10. Walls AC, Park YJ, Tortorici MA, Wall A, McGuire AT, et al. (2020) Structure, Function, and Antigenicity of the SARS-CoV-2 Spike Glycoprotein. Cell 181: 281-92.

11. Xu H, Zhong L, Deng J, Peng J, Dan H, et al. (2020) High expression of ACE2 receptor of 2019-nCoV on the epithelial cells of oral mucosa. Int J Oral Sci 12: 8 .

12. Wong SK, Li W, Moore MJ, Choe H, Farzan M (2004) A 193-amino acid fragment of the SARS coronavirus $S$ protein efficiently binds angiotensin-converting enzyme 2. J Biol Chem 279: 3197-3201.
13. Tay MZ, Poh CM, Rénia L, MacAry PA, Ng LFP (2020) The trinity of COVID-19: immunity, inflammation and intervention. Nat Rev Immunol 20: 363-374.

14. Hoffmann $\mathrm{M}$, Kleine-Weber $\mathrm{H}$, Schroeder $\mathrm{S}$, Krüger $\mathrm{N}$, Herrler $\mathrm{T}$, et al. (2020) SARS-CoV-2 Cell Entry Depends on ACE2 and TMPRSS2 and Is Blocked by a Clinically Proven Protease Inhibitor. Cell 181: 271. e8-280.e8.

15. Mason RJ (2020) Pathogenesis of COVID-19 from a cell biology perspective. Eur Respir J 55: 2000607.

16. Chan JF, Yuan S, Kok KH, To KK, Chu H, et al. (2020) A familial cluster of pneumonia associated with the 2019 novel coronavirus indicating person-to-person transmission: a study of a family cluster. Lancet 395: 514-523.

17. Huang C, Wang $Y$, Li X, Ren L, Zhao J, et al. (2020) Clinical features of patients infected with 2019 novel coronavirus in Wuhan, China. Lancet 395: 497-506.

18. Branco ACCC, Yoshikawa FSY, Pietrobon AJ, Sato MN (2018) Role of Histamine in Modulating the Immune Response and Inflammation. Mediators Inflamm 2018: 9524075.

19. Gasteiger G, D'Osualdo A, Schubert DA, Weber A, Bruscia EM, et al. (2017) Cellular Innate Immunity: An Old Game with New Players. J Innate Immun 9: 111-125.

20. Hou YJ, Okuda K, Edwards CE, Martinez DR, Asakura T, et al. (2020) SARS-CoV-2 Reverse Genetics Reveals a Variable Infection Gradient in the Respiratory Tract. Cell 182: 429.e14-446.e14.

21. Cristiani L, Mancino E, Matera L, Nenna R, Pierangeli A, et al. (2020) Will children reveal their secret? The coronavirus dilemma. Eur Respir J 55: 2000749.

22. Prussin C, Metcalfe DD (2003) 4. IgE, mast cells, basophils, and eosinophils. J Allergy Clin Immunol 111: S486-S494.

23. Halova I, Draberova L, Draber P (2012) Mast cell chemotaxischemoattractants and signaling pathways. Front Immunol 3: 119.

24. Dawicki W, Marshall JS (2007) New and emerging roles for mast cells in host defence. Curr Opin Immunol 19: 31-38.

25. Urb M, Sheppard DC (2012) The Role of Mast Cells in the Defence against Pathogens. PLoS Pathog 8: e1002619.

26. Graham AC, Temple RM, Obar JJ (2015) Mast cells and influenza A virus: Association with allergic responses and beyond. Front Immunol 6: 238.

27. Abraham SN, St John AL (2010) Mast cell-orchestrated immunity to pathogens. Nat Rev Immunol 10: 440-452.

28. Lu L, Kulka M, Unsworth LD (2017) Peptide-mediated mast cell activation: ligand similarities for receptor recognition and proteaseinduced regulation. J Leukoc Biol 102: 237-251.

29. de Cássia Campos MR, Toso VD, de Souza DA Jr, Vieira GV, da Silva $E Z$, et al. (2014) Differential effects of chemoattractants on mast cell recruitment in vivo. Cell Immunol 289: 86-90.

30. Yu Y, Blokhuis B, Garssen J, Redegeld F (2016) Non-IgE mediated mast cell activation. Eur J Pharmacol 778: 33-43.

31. da Silva EZ, Jamur MC, Oliver C (2014) Mast cell function: a new vision of an old cell. J Histochem Cytochem 62: 698-738.

32. Thangam EB, Jemima EA, Singh H, Baig MS, Khan M, et al. (2018) The Role of Histamine and Histamine Receptors in Mast Cell-Mediated Allergy and Inflammation: The Hunt for New Therapeutic Targets. Front Immunol 9: 1873. 
33. Min HK, Kim KW, Lee S, Kim H (2020) Roles of mast cells in rheumatoid arthritis. Korean J Intern Med 35: 12-24

34. Tobaiqy $M$, Qashqary $M$, Al-Dahery S, Mujallad A, Hershan AA, et al. (2020) Therapeutic management of patients with COVID-19: a systematic review. Infection Prevention in Practice 2: 100061.

35. Raymond M, Ching-A-Sue G, Van Hecke O (2020) Mast cell stabilisers leukotriene antagonists and antihistamines: A rapid review of the evidence for their use in COVID-19. CEBM, Nuffield Department of Primary Care Health Sciences, University of Oxford, UK.

36. Jennings S, Russell N, Jennings B, Slee V, Sterling L, et al. (2014) The Mastocytosis Society survey on mast cell disorders: patient experiences and perceptions. J Allergy Clin Immunol Pract 2: 70-76.

37. Afrin LB (2013) Presentation, diagnosis and management of mast cell activation syndrome. In: Murray DB (eds) Mast cells: Phenotypic features, biological functions and role in immunity. Nova Science Publishers, Inc. United States 155-232.

38. Valent P, Akin C, Arock M, Brockow K, Butterfield JH, et al. (2012) Definitions, criteria and global classification of mast cell disorders with special reference to mast cell activation syndromes: a consensus proposal. Int Arch Allergy Immunol 157: 215-225.

39. Theoharides TC, Valent P, Akin C (2015) Mast Cells, Mastocytosis, and Related Disorders. N Engl J Med 373: 163-172.

40. Kritas SK, Ronconi G, Caraffa A, Gallenga CE, Ross R, et al. (2020) Mast cells contribute to coronavirus-induced inflammation: new anti-inflammatory strategy. J Biol Regul Homeost Agents 34: 9-14.

41. Gallenga CE, Pandolfi F, Caraffa Al, Kritas SK, Ronconi G, et al. (2019) Interleukin-1 family cytokines and mast cells: activation and inhibition. J Biol Regul Homeost Agents 33: 1-6.

42. Huang I, Pranata R (2020) Lymphopenia in severe coronavirus disease-2019 (COVID-19): systematic review and meta-analysis. J Intensive Care 8:36.

43. Liu Z, Li X, Qiu S, Yu Y, Li M, et al. (2017) Vitamin D contributes to mast cell stabilization. Allergy 72: 1184-1192.

44. Akdis C, Jutel M, Akdis M (2008) Regulatory effects of histamine and histamine receptor expression in human allergic immune responses. Chem Immunol Allergy 94: 67-82.

45. Marone G, Gentile M, Petraroli A, De Rosa N, Triggiani M (2001) Histamine-induced activation of human lung macrophages. Int Arch Allergy Immunol 124: 249-252.

46. Jutel M, Blaser $\mathrm{K}$, Akdis CA (2006) The role of histamine in regulation of immune responses. Chem Immunol Allergy 91: 174-187.

47. Ferstl R, Akdis CA, O' Mahony L (2012) Histamine regulation of innate and adaptive immunity. Front Biosci (Landmark Ed) 17: 40-53.

48. O' Mahony L, Akdis M, Akdis CA (2011) Regulation of the immune response and inflammation by histamine and histamine receptors. J Allergy Clin Immunol 128: 1153-1162.

49. Jutel M, Watanabe T, Klunker S, Akdis M, Thomet OA, et al. (2001) Histamine regulates T-cell and antibody responses by differential expression of $\mathrm{H} 1$ and $\mathrm{H} 2$ receptors. Nature 413: 420-425.

50. Yip KH, Kolesnikoff N, Yu C, Hauschild N, Taing H, et al. (2014) Mechanisms of Vitamin $D_{3}$ metabolite repression of IgE-dependent mast cell activation. J Allergy Clin Immunol 133: 1356-1364.

51. Martineau A, Cates C, Urashima M, Jensen M, Griffiths A, et al. (2016) Vitamin $D$ for the management of asthma. Cochrane Database Syst Rev 9: CD011511.
52. Barcik W, Pugin B, Brescó MS, Westermann P, Rinaldi A, et al. (2019) Bacterial secretion of histamine within the gut influences immune responses within the lung. Allergy 74: 899-909.

53. Baek WK, Sohn SY, Mahgoub A, Hage R (2020) A Comprehensive Review of Severe Acute Respiratory Syndrome Coronavirus 2. Cureus 12: e7943.

54. Triggiani M, Gentile M, Secondo A, Granata F, Oriente A, et al. (2001) Histamine induces exocytosis and IL-6 production from human lung macrophages through interaction with $\mathrm{H} 1$ receptors. J Immunol 166: 4083-4091.

55. Mommert S, Gschwandtner M, Koether B, Gutzmer R, Werfel T (2012) Human memory Th17 cells express a functional histamine H4 receptor. Am J Pathol 180: 177-185.

56. Trinchieri G (1995) Interleukin-12 a proinflammatory cytokine with immunoregulatory function that bridge innate resistance and antigen specific adaptive immunity. Ann Rev Immunol 13: 251-276.

57. Trinchieri G (2003) Interleukin-12 and the regulation of innate resistance and adaptive immunity. Nat Rev Immunol 3: 133-146.

58. Presky DH, Yang H, Minetti LJ, Chua AO, Nabavi N, et al. (1996) A functional interleukin 12 receptor complex is composed of two beta-type cytokine receptor subunits. Proc Natl Acad Sci U S A 93: 14002-14007.

59. Trinchieri G (1998) Interleukin-12: a cytokine at the interface of inflammation and immunity. Adv Immunol 70: 83-243.

60. Trinchieri G, Pflanz S, Kastelein R (2003) The IL-12 family of heterodimeric cytokines: new players in the regulation of $\mathrm{T}$ cell responses. Immunity 19: 641-644.

61. Germann T, Rude E, Schmitt E (1995) The influence of IL12 on the development of Th1 and Th2 cells and its adjuvant effect for humoral immune responses. Res Immunol 146: 481-486.

62. Buchanan JM, Vogel LA, Van Cleave VH, Metzger DW (1995) Interleukin 12 alters the isotype-restricted antibody response of mice to hen eggwhite lysozyme. Int Immunol 7: 1519-1528.

63. Diefenbach $A$, Schindler $H$, Rollinghoff $M$, Yokoyama WM, Bogdan C (1999) Requirement for type 2 NO synthase for IL-12 signaling in innate immunity. Science 284: 951-955.

64. Bertagnolli MM, Lin BY, Young D, Herrmann SH (1992) IL-12 augments antigen-dependent proliferation of activated $\mathrm{T}$ lymphocytes. Immunol 149: 3778-3783.

65. Chan AC, Irving BA, Fraser JD, Weiss A (1991) The zeta chain is associated with a tyrosine kinase and upon T-cell antigen receptor stimulation associates with ZAP-70, a 70-kDa tyrosine phosphoprotein. Proc Natl Acad Sci U S A 88: 9166-9170.

66. Houldsworth A, Metzner M, Rossol S, Shaw S, Kaminski E, et al. (2005) Polymorphisms in the Interleukin-12B Gene and Outcome of HCV Infection. J Interferon Cytokine Res 25: 271-276.

67. D'Andrea A, Aste-Amezaga M, Valiante NM, Ma X, Kubin M, et al (1993) Interleukin 10 (IL-10) inhibits human lymphocyte interferon gamma-production by suppressing natural killer cell stimulatory factor/IL-12 synthesis in accessory cells. J Exp Med 178: 1041-1048.

68. Gauzzi M, Fantuzzi L (2020) Reply to Jakovac: COVID-19, Vitamin D, and type I interferon. Am J Physiol Endocrinol Metab 319: E245-E246.

69. Dorman SE, Holland SM (2000) Interferon-gamma and interleukin-12 pathway defects and human disease. Cytokine Growth Factor Rev 11: 321-33. 
70. Rojas M, Rodríguez Y, Monsalve DM, Acosta-Ampudia Y, Camacho B, et al. (2020) Convalescent plasma in COVID-19: Possible mechanisms of action. Autoimmunity reviews 19: 102554.

71. Wan S, Yi Q, Fan S, Lv J, Zhang X, et al. (2020). Relationships among lymphocyte subsets, cytokines, and the pulmonary inflammation index in coronavirus (COVID-19) infected patients. Br J Haematol 189: 428-437.

72. Kolls JK, Lindén A (2004) Interleukin-17 family members and inflammation. Immunity 21: 467-476.

73. Lin AM, Rubin CJ, Khandpur R, Wang JY, Riblett MB, et al. (2011) Mast cells and neutrophils release IL-17 through extracellular trap formation in psoriasis. J Immunol 187: 490-500.

74. Martin DA, Towne JE, Kricorian G, Klekotka P, Gudjonsson JE, et al. (2013) The emerging role of IL-17 in the pathogenesis of psoriasis: preclinical and clinical findings. J Invest Dermatol 133: 17-26.

75. Starnes T, Broxmeyer HE, Robertson MJ, Hromas R (2002) Cutting edge: IL-17D, a novel member of the IL-17 family, stimulates cytokine production and inhibits hemopoiesis. J Immunol 169: 642-646.

76. Yoshimoto $T$ (2018) The Hunt for the Source of Primary Interleukin-4: How We Discovered That Natural Killer T Cells and Basophils Determine $\mathrm{T}$ Helper Type 2 Cell Differentiation in vivo. Front Immunol 9: 716 .

77. Cheung PFY, Wong CK, Lam CWK (2008) Molecular mechanisms of cytokine and chemokine release from eosinophils activated by IL17A, IL-17F, and IL-23: implication for Th17 lymphocytes-mediated allergic inflammation. J Immunol 180: 5625-5635.

78. Liu J, Liu Y, Xiang P, Pu L, Xiong $\mathrm{H}$, et al. (2020) Neutrophil-tolymphocyte ratio predicts severe illness patients with 2019 novel coronavirus in the early stage. medRxiv.

79. Lin L, Lu L, Cao W, Li T (2020) Hypothesis for potential pathogenesis of SARS-CoV-2 infection--a review of immune changes in patients with viral pneumonia. Emerg Microbes Infect 9: 727-737.

80. Zheng HY, Zhang M, Yang CX, Xhang N, Wang XC, et al. (2020) Elevated exhaustion levels and reduced functional diversity of $\mathrm{T}$ cells in peripheral blood may predict severe progression in COVID-19 patients. Cell Mol Immunol 17: 541-543.

81. Lammas DA, Casanova JL, Kumararatne DS (2000) Clinical consequences of defects in the IL-12-dependent interferon-gamma (IFN-gamma) pathway. Clin Exp Immunol 121: 417-425.

82. Ma X, Yan W, Zheng H, Du Q, Zhang L, et al. (2015) Regulation of IL10 and IL-12 production and function in macrophages and dendritic cells. F1000Res 4: F1000.

83. D’Ambrosio D, Cippitelli M, Cocciolo MG, Mazzeo D, Di Lucia P, et al. (1998) Inhibition of IL-12 production by 1,25-dihydroxyVitamin $\mathrm{D}_{3}$. Involvement of NF-kappaB downregulation in transcriptional repression of the p40 gene. J Clin Invest 101: 252-262.

84. Martinez NE, Sato F, Kawai E, Omura S, Chervenak RP, et al. (2012) Regulatory T cells and Th17 cells in viral infections: implications for multiple sclerosis and myocarditis. Future Virol 7: 593-608.

85. Hou W, Kang HS, Kim BS (2009) Th17 cells enhance viral persistence and inhibit T cell cytotoxicity in a model of chronic virus infection. $J$ Exp Med 206: 313-328.

86. Sun H, Kim D, Li X, Kiselinova M, Ouyang Z, et al. (2015) Th1/17 Polarization of CD4 T Cells Supports HIV-1 Persistence during Antiretroviral Therapy. J Virol 89: 11284-11293.
87. Ye Yi, Lagniton PNP, Ye S, Li E, Xu RH (2020) COVID-19: what has been learned and to be learned about the novel coronavirus disease. Int J Biol Sci 16: 1753-1766.

88. Li C, Yang P, Sun Y, Li T, Wang C, et al. (2012) IL-17 response mediates acute lung injury induced by the 2009 pandemic influenza A (H1N1) virus. Cell Res 22: 528-538.

89. Wacleche VS, Goulet JP, Gosselin A, Monteiro P, Soudeyns H, et al. (2016) New insights into the heterogeneity of Th17 subsets contributing to HIV-1 persistence during antiretroviral therapy. Retrovirology 13: 59.

90. Wu D, Yang XO (2020) TH17 responses in cytokine storm of COVID-19: An emerging target of JAK2 inhibitor Fedratinib. J Microbiol Immunol Infect 53: 368-370.

91. Zhang H, Shih DQ, Zhang X (2013) Mechanisms underlying effects of 1,25-DihydroxyVitamin $D_{3}$ on the Th17 cells. Eur J Microbiol Immunol (Bp) 3: 237-240.

92. Hamzaoui A, Berraies A, Hamdi B, Kaabachi W, Ammar J, et al. (2014) Vitamin $D$ reduces the differentiation and expansion of Th17 cells in young asthmatic children. Immunobiology 219: 873-879.

93. Adriana SD, Brown AJ, Slatopolsky E (2005) Vitamin D. Am J Physiol Renal Physiol 289: F8-F28.

94. Wöbke TK, Sorg BL, Steinhilber D (2014) Vitamin D in inflammatory diseases. Front Physiol 5: 244.

95. Bhalla AK, Amento EP, Krane SM (1986) Differential effects of 1,25-dihydroxyVitamin $D_{3}$ on human lymphocytes and monocyte/ macrophages: inhibition of interleukin-2 and augmentation of interleukin-1 production. Cell Immunol 98: 311-322.

96. Arshi S, Fallahpour M, Nabavi M, Bemanian MH, Javad-Mousavi SA, et al. (2014) The effects of Vitamin D supplementation on airway functions in mild to moderate persistent asthma. Ann Allergy Asthma Immunol 113: 404-409.

97. Hall SC, Fischer KD, Agrawal DK (2016) The Impact of Vitamin D on Asthmatic Human Airway Smooth Muscle. Expert Rev Respir Med 10: 127-135.

98. Lagishetty V, Liu NQ, Hewison M (2011) Vitamin D metabolism and innate immunity. Mol Cell Endocrinol 347: 97-105.

99. Li YC (2011) Molecular mechanism of Vitamin D in the cardiovascular system. J Investig Med 59: 868-871.

100. Xu J, Yang J, Chen J, Luo Q, Zhang Q, et al. (2017) Vitamin D alleviates lipopolysaccharide-induced acute lung injury via regulation of the renin angiotensin system. Molecular Medicine Reports 16: 74327438.

101. Scragg R, Sowers MF, Bell C (2007) Serum 25-hydroxyVitamin D, ethnicity, and blood pressure in the Third National Health and Nutrition Examination Survey. Am J Hypertens 20: 713-719.

102. Glass D, Lens M, Swaminathan R, Spector TD, Bataille V (2009) Pigmentation and Vitamin D metabolism in Caucasians: low Vitamin D serum levels in fair skin types in the UK. PLoS One 4: e6477.

103. Rockell JEP, Skeaff CM, Williams SM, Green TJ (2008) Association between quantitative measures of skin color and plasma 25-hydroxyVitamin D. Osteoporos Int 19: 1639-1642.

104. Chertow BS, Sivitz WI, Baranetsky NG, Clark SA, Waite A, et al. (1983) Cellular mechanisms of insulin release: the effects of Vitamin $D$ deficiency and repletion on rat insulin secretion. Endocrinology 13: 1511-1518. 
105. Miao Z, Wang S, Wang Y, Guo Y, Zhang J, et al. (2020) A Potential Linking between Vitamin D and Adipose Metabolic Disorders. Can J Gastroenterol Hepatol 2020: 2656321.

106. Jones P, Lucock M, Chaplin G, Jablonski NG, Veysey M, et al. (2020) Distribution of variants in multiple Vitamin D-related loci (DHCR7/ NADSYN1, GC, CYP2R1, CYP11A1, CYP24A1, VDR, RXR $\alpha$ and RXRY) vary between European, East-Asian and Sub-Saharan Africanancestry populations. Genes Nutr 15: 5.

107. Sirajudeen S, Shah I, Al Menhali A (2019) A Narrative Role of Vitamin D and Its Receptor: With Current Evidence on the Gastric Tissues. Int J Mol Sci 20: 3832.

108. Uitterlinden AG, Fang $Y$, Van Meurs JBJ, Pols HAP, Van Leeuwen JPTM (2004) Genetics and biology of Vitamin D receptor polymorphisms. Gene 338: 143-156.

109. Valdivielso JM, Fernandez E (2006) Vitamin D receptor polymorphisms and diseases. Clin Chim Acta 371: 1-12.

110. Fioletov V, Kerr JB, Fergusson A (2010) The UV index: definition, distribution and factors affecting it. Can J Public Health 101: 15-19.

111. Dai T, Vrahas MS, Murray CK, Hamblin MR (2012) Ultraviolet C irradiation: an alternative antimicrobial approach to localized infections? Expert Rev Anti Infect Ther 10: 185-195.

112. McDevitt JJ, Milton DK, Rudnick SN, First MW (2008) Inactivation of poxviruses by upper-room UVC light in a simulated hospital room environment. PLoS One 3: e3186.

113. Sagripanti JL, Lytle CD (2011) Sensitivity to ultraviolet radiation of Lassa, vaccinia, and Ebola viruses dried on surfaces. Arch Virol 156: 489-494.

114. lanevski A, Zusinaite E, Shtaida N, Kallio-Kokko H, Valkonen M, et al. (2019) Low Temperature and Low UV Indexes Correlated with Peaks of Influenza Virus Activity in Northern Europe during 2010-2018. Viruses 11: 207

115. Hashem AM, Hassan AM, Tolah AM, Alsaadi AM, Abunada Q, et al. (2019) Amotosalen and ultraviolet A light efficiently inactivate MERS-coronavirus in human platelet concentrates. Transfus Med 29: 434-441.

116. Pinna D, Sampson-Johannes A, Clementi M, Poli G, Rossini S, et al. (2005) Amotosalen photochemical inactivation of severe acute respiratory syndrome coronavirus in human platelet concentrates. Transfus Med 15: 269-276.

117. Vatansever F, Ferraresi $C$, Pires de Sousa $M$, Yin R, Rineh A, et al. (2013) Can biowarfare agents be defeated with light? Virulence 4 796-825.

118. Costa L, Faustino M, Neves M, Cunha A, Almeida A (2012) Photodynamic inactivation of mammalian viruses and bacteriophages. Viruses 4: 1034-1074.

119. Ikehata H, Ono T (2011) The mechanisms of UV mutagenesis. J Radiat Res. 52: 115-125.

120. Yuan W, Pan W, Kong J, Zheng W, Szeto FL, et al. (2007) 1,25-dihydroxyVitamin $D_{3}$ suppresses renin gene transcription by blocking the activity of the cyclic AMP response element in the renin gene promoter. J Biol Chem 282: 29821-29830.

121. Simon CB, Lee-McMullen B, Phelan D, Gilkes J, Carter CS, et al. (2015) The renin-angiotensin system and prevention of age-related functional decline: where are we now? Age (Dordr) 37: 9753.

122. Danser AHJ, Epstein M, Batlle D (2020) Renin-Angiotensin
System Blockers and the COVID-19 Pandemic: At Present There Is No Evidence to Abandon Renin-Angiotensin System Blockers. Hypertension 75: 1382-1385

123. Kai H, Kai M (2020) Interactions of coronaviruses with ACE2, angiotensin II, and RAS inhibitors-lessons from available evidence and insights into COVID-19. Hypertens Res 43: 648-654.

124. Becker BF (2011) All because of the mast cell: blocking the angiotensin receptor-1 should be better than inhibiting ACE (theoretically). Cardiovasc Res 92: 7-9.

125. Dijkman R, Jebbink MF, Deijs M, Milewska A, Pyrc K, et al. (2012) Replication-dependent downregulation of cellular angiotensinconverting enzyme 2 protein expression by human coronavirus NL63. J Gen Virol 93: 1924-1929.

126. de Simone G (2020) Position Statement of the ESC Council on Hypertension on ACE-Inhibitors and Angiotensin Receptor Blockers. European Society of Cardiology.

127. Zhang P, Zhu L, Cai J, Lei F, Qin JJ, et al. (2020) Association of Inpatient Use of Angiotensin Converting Enzyme Inhibitors and Angiotensin II Receptor Blockers with Mortality Among Patients With Hypertension Hospitalized With COVID-19. Circ Res 126: 1671-1681.

128. Imai Y, Kuba K, Rao S, Huan Y, Guo F, et al. (2005) Angiotensinconverting enzyme 2 protects from severe acute lung failure. Nature 436: $112-116$

129. Banu N, Panikar SS, Leal LR, Leal AR (2020) Protective role of ACE2 and its downregulation in SARS-CoV-2 infection leading to Macrophage Activation Syndrome: Therapeutic implications. Life sciences 256: 117905 .

130. Burnier M (2001) Angiotensin II Type 1 Receptor Blockers. Circulation 103: 904-912.

131. Tukaj S, Trzonkowski P, Tukaj C (2012) Regulatory effects of 1,25-dihydroxyVitamin $D_{3}$ on vascular smooth muscle cells. Acta biochim Pol 5: 395-400

132. Jakovac H (2020) COVID-19 and hypertension: is the HSP60 culprit for the severe course and worse outcome? Am J Physiol Heart Circ Physiol 319: H793-H796.

133. Sahota O (2014) Understanding Vitamin D deficiency. Age Ageing 43: 589-591.

134. Nakajima M, Kawaguchi M, Ota K, Fujita J, Matsukura S, et al. (2017) IL-17F induces IL-6 via TAK1-NFKB pathway in airway smooth muscle cells. Immun Inflamm Dis 5: 124-131.

135. Molderings GJ, Haenisch B, Brettner S, Homann J, Menzen M, et al. (2016) Pharmacological treatment options for mast cell activation disease. Naunyn-Schmiedebergs Arch Pharmacol 389: 671-694.

136. Arminjon SD, Gonnet DS, Kaji DE, Rezeau-Frantz DH (2020) Antihistamines as a therapeutic care plan of COVID-19 About 26 cases.

137. Morrison J, Rathore APS, Mantri CK, Aman SAB, Nishida A, et al. (2017) Transcriptional Profiling Confirms the Therapeutic Effects of Mast Cell Stabilization in a Dengue Disease Model. J Virol 91: e00617-e00717.

138. Li Z, Celestin J (2015) Ketotifen: A Role in the Treatment of Idiopathic Anaphylaxis. American Academy of Allergy, Asthma and Immunology Annual Meeting. Houston.

139. Eldanasory OA, Eljaaly K, Memish ZA, Al-Tawfiq JA (2020) Histamine release theory and roles of antihistamine in the treatment of cytokines storm of COVID-19. Travel Med Infect Dis 37: 101874.

Citation: Houldsworth A (2021) The Perfect Storm: Review: Immune Dysregulation in Severe COVID-19 and the Possible Role of Mast 
140. Lee J, van Hecke O, Roberts N (2020) Vitamin D: A rapid review of the evidence for treatment or prevention in COVID-19. The Centre for Evidence-Based Medicine (CEBM).

141. Liu F, Li L, Xu M, Wu J, Luo D, et al. (2020) Prognostic value of interleukin-6, C-reactive protein, and procalcitonin in patients with COVID-19. J Clin Virol 127: 104370.

142. Pereira M, Dantas Damascena A, Galvão Azevedo LM, Almeida Oliveira TD, da Mota Santana J (2020) Vitamin D deficiency aggravates COVID-19: systematic review and meta-analysis. Crit Rev Food Sci Nutr 4: 1-9.

143. Jain A, Chaurasia R, Sengar NS, Singh M, Mahor S, et al. (2020) Analysis of Vitamin $D$ level among asymptomatic and critically ill COVID-19 patients and its correlation with inflammatory markers. Sci Rep 10: 20191.

144. Mariani J, Giménez VMM, Bergam I, Tajer C, Antonietti L, et al. (2020) Association Between Vitamin D Deficiency and COVID-19 Incidence, Complications, and Mortality in 46 Countries: An Ecological Study. Health Secur.

145. Katz J, Yue S, Xue W (2020) Increased risk for COVID-19 in patients with Vitamin D deficiency. Nutrition 84: 111106.
146. Luo $X$, Liao $Q$, Shen $Y$, Huijunet $L$, Liming $C$, et al. (2021) Vitamin D Deficiency Is Inversely Associated with COVID-19 Incidence and Disease Severity in Chinese People. J Nutr 151: 98-103.

147. Entrenas Castillo M, Entrenas Costa LM, Vaquero Barrios JM, Alcalá Díaz JF, Miranda JP, et al. (2020) Effect of calcifediol treatment and best available therapy versus best available therapy on intensive care unit admission and mortality among patients hospitalized for COVID-19: A pilot randomized clinical study. J Steroid Biochem Mol Biol 203: 105751.

148. Ling SF, Broad E, Murphy R, Pappachan JM, Pardesi-Newton S, et al. (2020) High-Dose Cholecalciferol Booster Therapy is Associated with a Reduced Risk of Mortality in Patients with COVID-19: A CrossSectional Multi-Centre Observational Study. Nutrients 12: 3799.

149. Tan CW, Ho LP, Kalimuddin S, Cherng BPZ, The YE, et al. (2020) Cohort study to evaluate the effect of Vitamin $D$, magnesium, and Vitamin $B_{12}$ in combination on progression to severe outcomes in older patients with coronavirus (COVID-19). Nutrition 79-80.

150. Ohaegbulam KC, Swalih M, Patel P, Smith MA, Perrin R (2020) Vitamin D Supplementation in COVID-19 Patients: A Clinical Case Series. Am J Ther 13: e485-e490. 